\title{
Pembuatan Animasi Pendaftaran Siswa Baru Pada SMAN 5 Kepahiang Berbasis Multimedia Linier
}

\author{
Agung Kharisma Hidayah ${ }^{1}$, Legi Sarwanto ${ }^{2}$, Sri Handayani ${ }^{3}$ \\ ${ }^{1}$ Dosen Fakultas Teknik, Universitas Muhammadiyah Bengkulu \\ Alamat: J1. Semeru Kota Bengkulu (Telp. (0736) 22765, Fax. (0736) 26161; e-mail: kharisma@umb.ac.id) \\ 2, 3 Fakultas Teknik Universitas Muhammadiyah Bengkulu \\ J1. Bali, Po. Box 118 (Telp. (0736) 22765 Fax. (0736) 26161; e-mail: legisw15@gmail.com, \\ yani3oyik@gmail.com)
}

Abstract-SMAN 5 Kepahiang is one of the schools in Kepahiang Regency. This is suitable for choice school for parents who want to entrust their children to high school level especially in Bermani Ilir environment. Kepahiang is less optimal service in providing information because many prospective students want to obtain information and registration procedures to become new students at SMAN 5 Kepahiang. Thus registration information is not fully understood by prospective new students. Therefore, researcher makes registration for new prospective students based on linear multimedia as additional media and support for publishing information about registration tutorials for all prospective students. Through this animation by using Blender software, Adobe Premiere Pro-software application, and file format that are produced from the process of making this animation is MP4 format. The type of content displayed in making this animation is video, sound, and text explaining, the tutorial for new student registration at SMAN 5 Kepahiang. Testing of video animation by using questionnaires that has been received an average of $82.8 \%$ answers.

Keyword: Multimedia, Registration Animation Video, Software Blender

Intisari-SMAN 5 Kepahiang merupakan salah satu sekolah di Kabupaten Kepahiang. Oleh sebab itu Sekolah SMAN 5 Kepahiang merupakan pilihan yang cocok bagi para orang tua yang ingin menyekolahkan anaknya ditingkat SMA khususnya di lingkungan Bermani Ilir, Kepahiang kurang maksimalnya pelayanan dalam pemberian informasi dikarenakan banyak calon siswa yang ingin mendapatkan informasi dan tata cara pendaftaran untuk menjadi siswa baru di SMAN 5 Kepahiang, Informasi pendaftaran yang ada tidak sepenuhnya dipahami oleh calon siswa baru. Untuk alasan ini, penulis membuat pendaftaran calon siswa baru yang didasarkan pada multimedia linear sebagai media tambahan dan dukungan untuk penerbitan informasi tentang tutorial pendaftaran untuk semua calonsiswa. Pembuatan animasi ini menggunakan perangkat lunak Blender dan aplikasi perangkat lunak Adobe Premiere Pro. format file yang dihasilkan dari proses pembuatan animasi ini adalah format MP4. jenis konten yang ditampilkan dalam pembuatan animasi ini adalah video, suara, dan teks yang menjelaskan tutorial pendaftaran siswa baru di SMAN 5 Kepahiang. Pengujian Vidio animasi menggunakan Angket yang telah didaptakan rata-rata jawaban $82.8 \%$.

Kata Kunci: Multimedia, Vidio Animasi Pendaftaran, Software Blender

\section{PENDAHULUAN}

Pada masa sekarang ini teknologi hampir menjadi kebutuhan yang sangat penting dalam kehidupan. Teknologi berjalan dengan sebuah kebutuhan manusia, sisi efisiensi, praktis serta murah adalah salah satu alasan kenapa teknologi dibutuhkan. Masyarakat sering kali tidak mau bersusah payah mencari informasi dengan mendatangi sumber informasi tersebut secara langsung maka teknologi informasi berbasis multimedia yang didalamnya dikemas seperti video gambar animasi, video profil dan sebagainya adalah salah satu jawaban dari permasalahan yang timbul. [1]

SMAN 5 Kepahiang merupakan salah satu sekolah di Kabupaten Kepahiang. Oleh sebab itu Sekolah SMAN 5 
Kepahiang merupakan pilihan yang cocok bagi para orang tua yang ingin menyekolahkan anaknya ditingkat SMA khususnya di lingkungan Bermani Ilir, Kepahiang. Hal ini berdampak pada peningkatan pendaftar calon siswa baru di SMAN 5 Kepahiang setiap tahunnya sehingga mengakibatkan kurang maksimalnya pelayanan dalam pemberian informasi dikarenakan banyak calon siswa yang ingin mendapatkan informasi dan tata cara pendaftaran untuk menjadi siswa baru di SMAN 5 Kepahiang, hal ini diakibatkan oleh kurangnya alternatif lain dalam pemberian informasi, sehingga hal ini mengakibatkan kurang maksimalnya pelayanan panitia penerimaan siswa baru dalam melayani dan memberikan informasi. Oleh karena itu sudah selayaknya pihak sekolah melalui panitia penerimaan siswa baru memiliki model alternatif lain yang dapat menjadi alat pemandu bagicalon siswa baru dalam penyampaian dan memberikan informasi.

Dari pokok yang melatarbelakangi kurangnya pendaftar, maka diharapkan dilakukan penelitian untuk Animasi Sistem Pendaftaran yang dirasa penting untuk dilakukan penelitian perancangan dan pembuatan film animasi 3D agar dapat memberi informasi tentang prosedur untuk pendaftaran siswa baru langkah demi langkah, sehingga dapat mengurangi terjadinya kebingungan dari para calon siswa baru di SMAN 5 Kepahiang.

Maka dari itu diharapkan proses pemberian informasi lewat film animasi 3D dengan menggunakan Software Blender $3 D$ dapat memberikan informasi tentang prosedur pendaftaran siswa baru, langkah demi langkah, sehingga dapat meringankan beban pelayanan pusat informasi, dalam memberikan pelayanan informasi kepada calon siswa baru. Blender adalah Software 3D pada komputer yang gratis dan open source, Blender digunakan untuk membuat film animasi, efek visual, dan vidio game. Software ini memiliki fitur pemodelan 3D, unwrapping $U V$, texturing, ringging and skinning, fluid and smoke simulation, particle simulation, animating, match moving, camera tracking, rendering, vidio editing, compositing and built-in game engine. Dimana kita dapat merancang dan membuat fim animasi 3D bukan hanya sebagai media hiburan dalam perfilman, tetapi juga dapat digunakan dalam berbagai bidang termasuk sebagai media sosialisasi visual, yang dapat membawa warna baru dalam penyampaian sebuah informasi [2].

Berdasarkan uraian latar belakang di atas, maka penulis tertarik mengangkat judul dalam penelitian ini yaitu:

"Pembuatan Animasi Pendaftaran Siswa Baru Pada SMAN 5 Kepahiang Berbasis Multimedia Linier". Dengan Trobosan ini diharapkan proses pemberian informasi pendaftaran melalui film animasi menjadi interaktif, menarik, dan dapat lebih mudah dipahami

\section{Tinjauan Pustaka}

Perancangan Tutorial Penerimaan Mahasiswa Baru Universitas Sam Ratulangi Berbasis Animasi 3D Oleh. Dengan meningkatnya pendaftaran calon mahasiswa baru setiap tahunnya membuat calon mahasiswa baru sulit untuk mendapatkan informasi langsung dari panitia pelayanan. Hal ini membuat calon mahasiswa baru kebingungan dengan prosedur pendaftaran mahasiswa baru, langkah demi langkah. Maka pihak Universitas sudah selayaknya memiliki sebuah media sosialisasi yang memudahkan dan dapat digunakan sebagai alat pemandu bagi calon mahasiswa baru dalam melakukan pendaftaran. Sehingga dibuatnya film animasi 3D agar dapat memberi informasi tentang prosedur pendaftaran calon mahasiswa baru, agar mengurangi terjadinya kebinggungan dari para calon mahasiswa. Pada pembuatan film animasi ini, proses dimulai dengan pembuatan konsep dan perancangan alur cerita. Setelah itu dilanjutkan menggunakan software blender untuk proses modeling dan teksturing objek. Objek-objek yang telah selesaidibuat akan ditata sesuai kebutuhan adegan dan dilakukan proses rigging serta skinning pada objek karakter. Proses selanjutnya ketahap animasi, hasil dari animasi ini akan dilanjutkan pada tahapan render, dan keluarannya adalah potongan- potongan adegan. Setelah proses pembuatan adegan selesai, maka akan

dilanjutkan dengan proses penggabungan adegan yang telah dibuat dan penambahan teks serta audio menggunakan softwareulead video studio 11. Tahap terakhir adalah proses rendering yang menghasilkan 
keluaran Video secara keseluruhan. Dengan trobosan ini diharapkan proses pemberian informasi lewat film animasi menjadi semakin interaktif, menarik dan dapat lebih mudah untuk dipahami.

Penelitian yang di lakukan dengan judul Film Animasi Pendaftaran Mahasiswa Baru Menggunakan 3Ds Max Pemodelan Mobil dan Animasi. Perkembangan teknologi sangat cepat sehingga menuntun kita untuk memperoleh informasi secara cepat dan mudah, yang dewasa ini dirasa semakin menjadi kebutuhan pokok yang mendesak. Suatu bentuk informasi yang mudah untuk disajikan yaitu dalam bentuk film animasi. Animasi merupakan suatu media yang lahir dari dua konvensi atau disiplin, yaitu film dan gambar. Film berakar dari fotografi, sedangkan animasi berakar dari dunia gambar, yaitu ilustrasi desain grafis. Melalui sejarahnya masing- masing, baik fotografi maupun ilustrasi mendapat dimensi dan wujud baru di dalam film live dan animasi. Pemodelan dan animasi mobil merupakan proses pembuatan objek mobil tiga dimensi dan membuat mobil tersebut dapat bergerak dengan menggunakan suatu metode. Metode yang digunakan untuk membuat mobil yaitu menggunakan pola dari objek mobil yang akan dibuat. Pola terdiri dari empat sisi yaitu sisi atas, depan, kanan, kiri.mobil dibuat dengan menggunakan kotak dan dibentuk mengikuti pola yang sudah disiapkan.Pembuatan animasi pendaftaran calon mahasiswa baru di Universitas Gunadarma diharapkan mampu memberikan kemudahan dan informasi interaktif jalur pendaftaran untuk masyarakat umum yang akan melakukan pendaftaran di Universitas Gunadarma. [3]

Penelitian yang di lakukan dengan judul Animasi Prosedur Pendaftaran Calon Mahasiswa Baru Universitas Sam Ratulangi dengan Augmented Reality oleh Riki Satria Watulingas, dkk.kurangnya media sosialisasi untuk para calon mahasiswa baru mengenai langkah demi langkah yang harus dilakukan untuk bisa terdaftar secara resmi sebagai mahasiswa di Universitas sam Ratulangi Manado sering kali menyebabkan para pendaftar merasa kesulitan untuk melakukan pendaftaran. Penelitian ini menghasilkan sebuah aplikasi yang diciptakan dengan pendekatan metode Multimedia Development Life Cycle untuk memberikan informasi prosedur pendaftaran calon mahasiswa baru dengan cara yang menarik dan mudah untuk dipahami. [4]

Berdasarkan tiga penelitian terdahulu yang membedakan penelitian ini yaitu objek penelitiannya. Dalam penelitian terdahulu objek penelitiannya untuk penerimaan mahasiswa baru, sedangkan dalam penelitian ini peneliti membuat animasi pendaftaran untuk siswa SMAN 5 Kepahiang. Penulis menggunakan Adobe Premier pro sebagai aplikasi penggabungan animasinya. Animasi yang dibuat pada penelitian ini menggambarkan pendaftaran siswa baru sampai menjadi siswa pada SMAN 5 Kepahiang.

\section{METOdOLOGI PENELITIAN}

Pada perancangan ini terdapat 3 tahap pembuatan yaitu Pra Produksi, Produksi, Post Produksi.

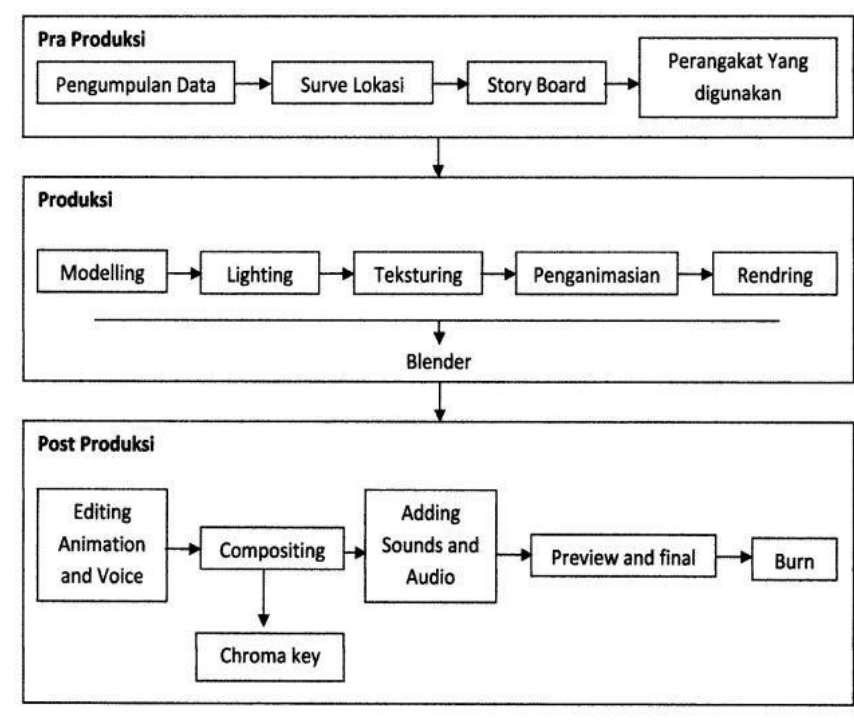

Gambar 1. Kerangka Penelitian

\section{A. Tahap Pra Produksi}

1. Pengumpulan Data

Pengumpulan data dalam penelitian ini dilakukan dengan cara:
a. Observasi (Pengamatan)
b. Dokumentasi
c. Wawancara

2. Survei Lokasi

Tahap survei lokasi merupakan tahap dimana peneliti mengamati lokasi untuk membuat konsep 
animasi dan bagian apa saja yang akan dianimasikan.

\section{Story board}

Story board adalah terjemahan berupa gambar cerita dari naskah yang sudah dibuat berisi tentang pengambilan sudut gambar, serta efek-efek khusus Fungsi story board adalah terjemahan isi skenario secara visual atau penggambaran secara singkat.

Tabel 1. Story Board

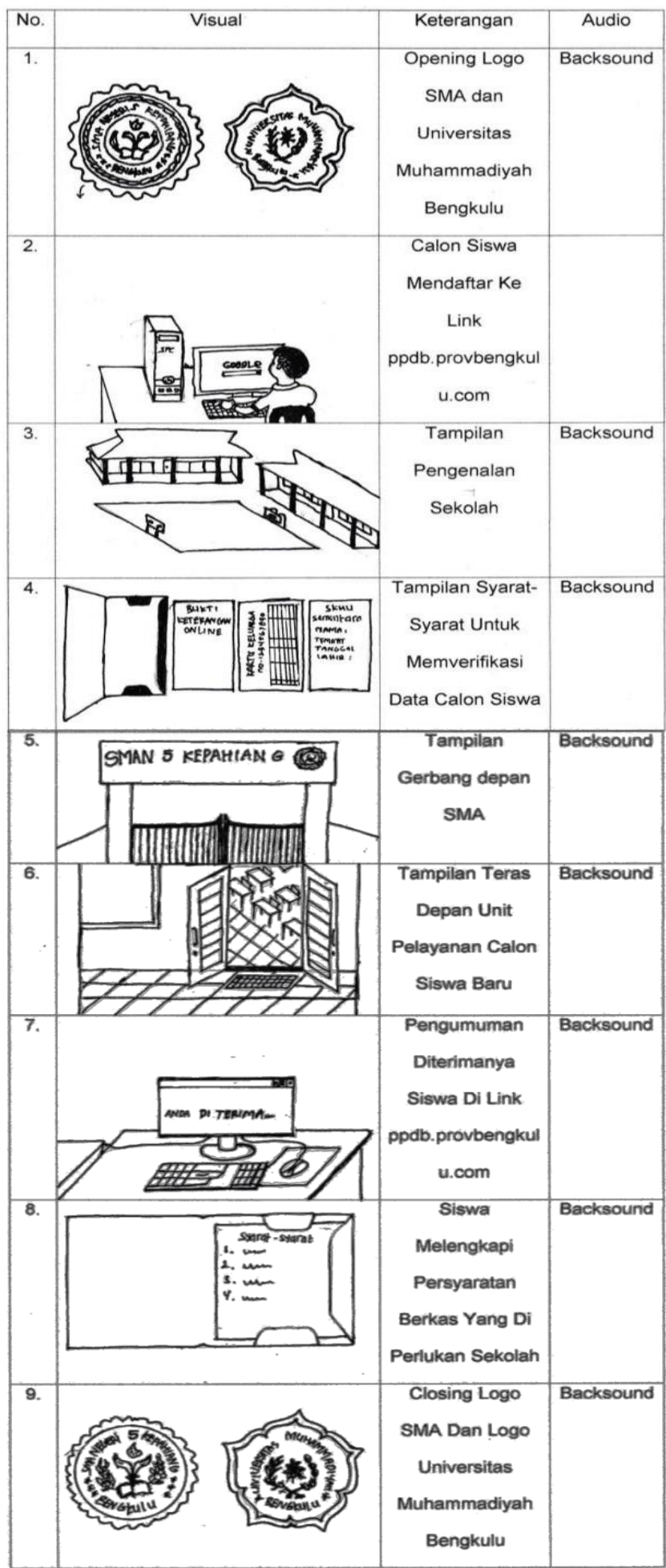

\section{Flowchart}

Bentuk flowchart dari proses perancangananimasi yang akan dibuat adalah sebagai berikut.

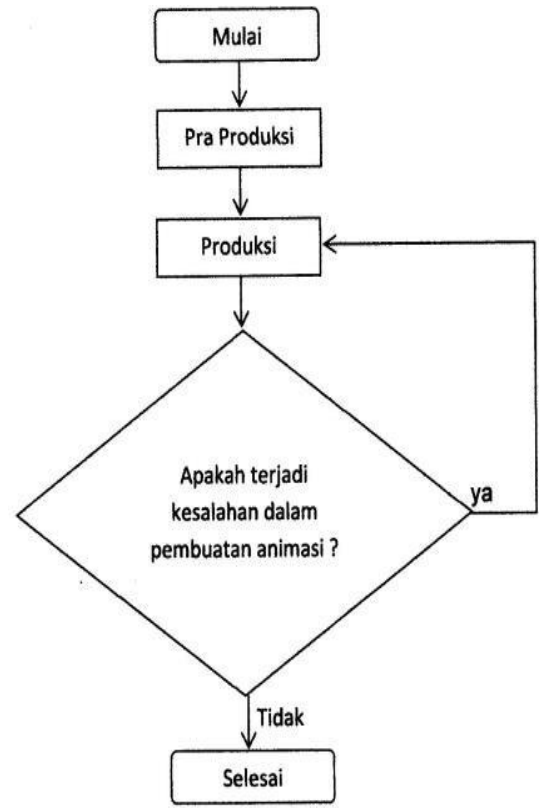

Gambar 2. Flowchart

\section{B. Tahap Produksi}

Tahap produksi adalah proses pembuatan animasi sebuah film dimulai. Dalam tahap ini terjadi beberapa pekerjaan yang dilakukan secara estafet dan teratur. Berikut adalah proses tahapan produksi :

\section{Modelling}

Penulis melakukan modelling di Software Blender. Baik itu Head Modelling, maupun Body modelling.

\section{Lighting}

Ini adalah proses penentuan intensitas cahaya pada film animasi yang diproduksi.

\section{Teksturing}

Supaya karakter yang dibuat mempunyai tekstur kulit yang alami atau natural, maka dilakukan tahap yang dinamakan Mapping Texture Character, untuk pemetaan material kulit pada karakter.

4. Penganimasian

Proses penganimasian disini mencakup proses ringging, skinning dan animasi.

\section{Rendering}

Setelah tahap animasi dilalui, selanjutnya adalah tahap rendering, menjadi suatu bentuk output berupa vidio. 


\section{IV.HASIL DAN PEMBAHASAN}

Pada penelitian ini menghasilkan film animasi pendaftaran siswa SMA baru pada SMAN 5 Kepahiang. Secara lengkap tahapan ini dilaksanakan sesuai dengan persiapan yang telah di lakukan pada tahap pra produksi.

\section{A. Modelling}

Dalam hal ini pembuatan video animasi ini di mulai dari pembuatan object-object yaitu ruangan kantor tempat operator menerima berkas dari para siswa-siswi baru,menggunakan Software Blender3D.

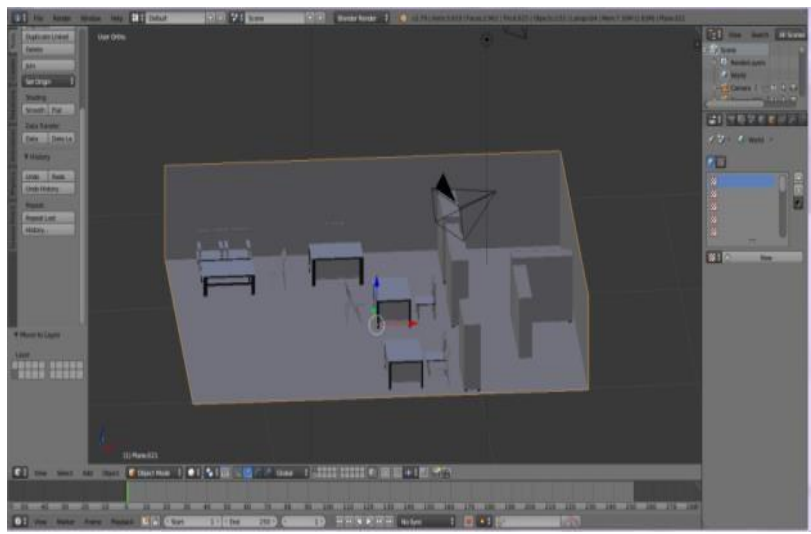

Gambar 3. Pembuatan Dinding Gedung

\section{B. Lighting}

Pencahayaan di sini bertujuan agar object dalam video animasi dapat terlihat, jika tidak tidak di terapkan maka object 3D dalam animasi ini tidak akan terlihat.

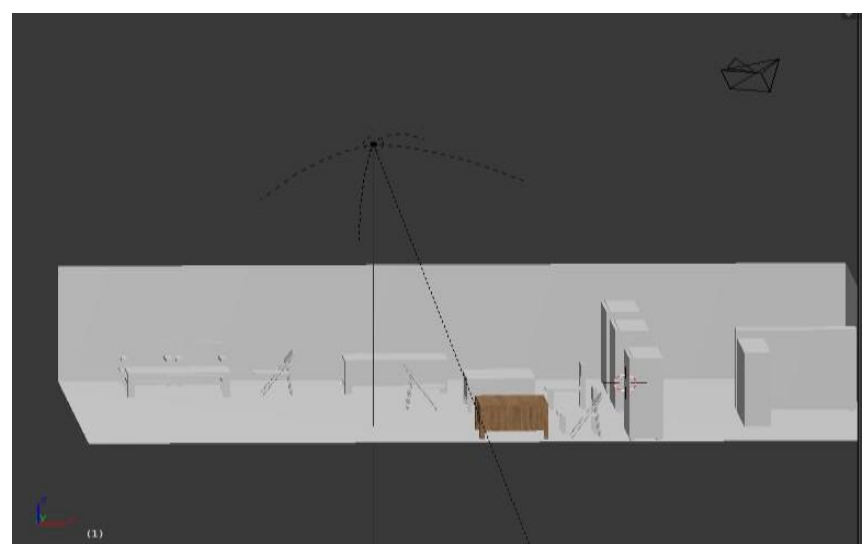

Gambar 4. Pemberian Lighting

\section{Teksturing}

Pemberian tekstur bertujuan agar animasi terlihat lebih nyata dan detail.

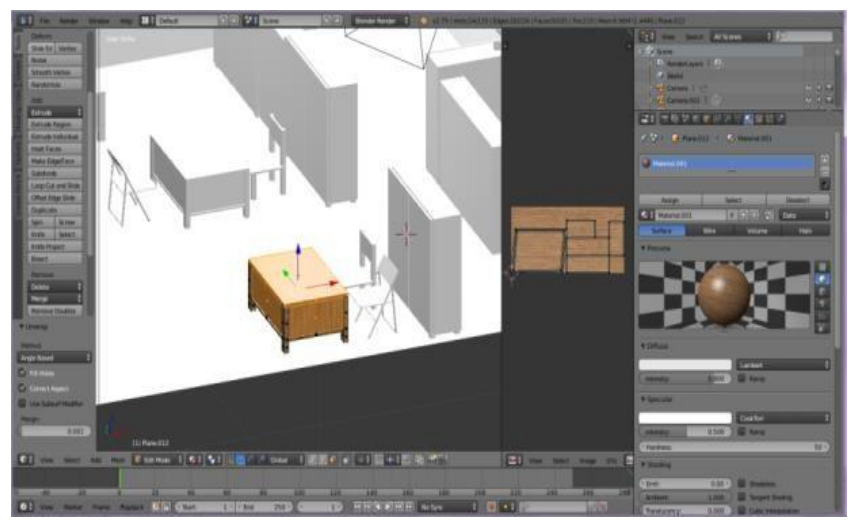

Gambar 5. Pemberian Tekstur

\section{Penganimasian}

Penganimasian adalah proses pembuatan gerakangerakan pada model animasi yang disesuai kandengan adegan dalam story board yang ceritanya akan diterapkan dalam film.

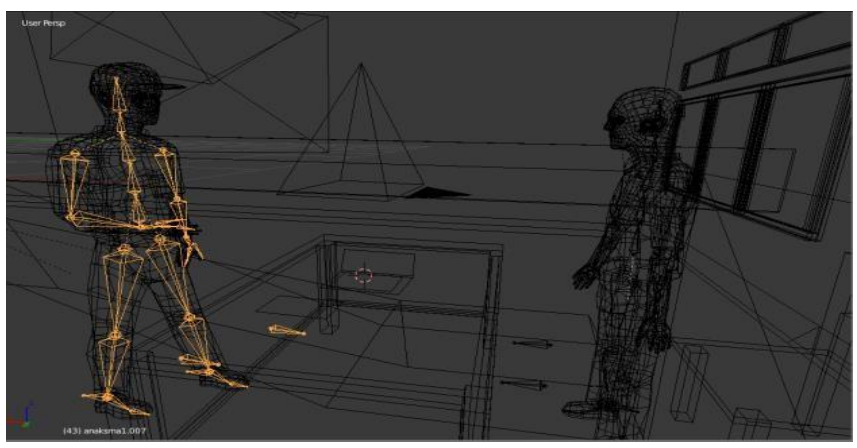

Gambar 6. Penganimasian Karakter

\section{E. Rendering}

Setelah semua proses pembuatan animasi selesai maka tahap terakhir adalah rendering yang bertujuan untuk memproses animasi dalam bentuk sebuah vidio.

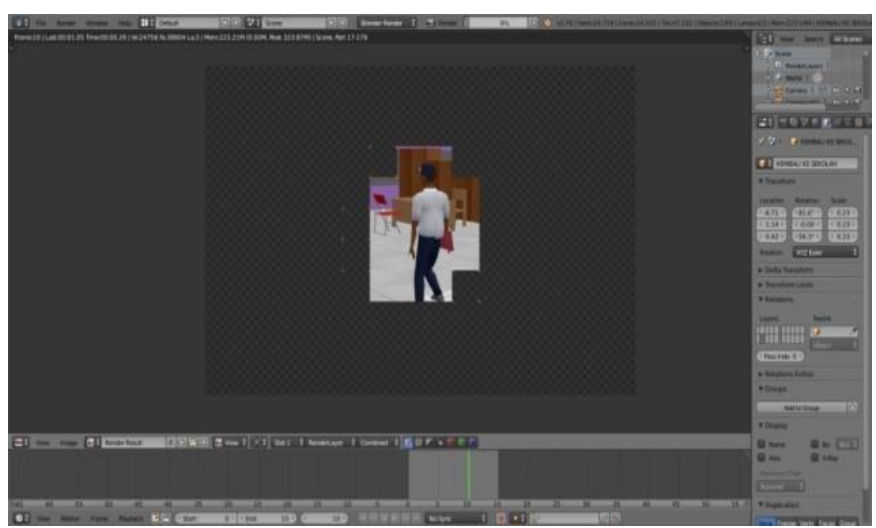

Gambar 7. Rendering 


\section{F. Compositing}

Compositing adalah tahap menyatukan scene per scene animasi yang sudah dirender menjadi sebuah video animasi yang utuh. Scene animasi disusun berdasarkan story board yang sudah dibuat. Biasanya diproses ini memotong bagian yang tidak diperlukan agar video lebih menarik nantinya dan dilakukan penambahan transisi.

\section{Post Produksi}

Tahap akhir dari suatu produksi animasi 3D ini meliputi:
1. Editing animation and voice Compositing
2. Additing sound and audio
3. Preview and final
4. Burning

\section{PENUTUP}

\section{A. Kesimpulan}

Berdasarkan bab-bab sebelum nya dalam penelitian ini, maka pada bagian penutup dapat diambil kesimpulan

1. Pembuatan Animasi Pendaftaran Siswa Baru Pada SMAN 5 Kepahiang Berbasis Multimedia Linier ini telah berhasil dirancang dengan Blender $3 D$ dan Adobe Premiere Pro.

2. Pembuatan Animasi Pendaftaran Siswa Baru Pada SMAN 5 Kepahiang Berbasis Multimedia Linier bertujuan untuk memberikan informasi tentang langkah-langkah pendaftaran calon siswa baru pada SMAN 5 Kepahiang.

3. Desain dan pembuatan animasi pendaftaran dibuat semirip mungkin dengan asli nya supaya dapat menyampaikan informasi dengan jelas.

4. Dari Pengujian Angket menunjukan bahwa jumlah persentase rata-rata jawaban responden berjumlah 82,8 \% Termasuk kategori "SANGAT BAIK".

\section{B. Saran}

Pada kesempatan ini penulis akan memberikan beberapa saran yang nantinya dapat berguna untuk pengembangan animasi.

1. Pembuatan Animasi Pendaftaran Siswa Baru pada SMAN 5 Kepahiang Berbasis Multimedia Linier ini sangat sederhana, sehingga di butuh kan perancangan yang lebih baik lagi.

2. Pembuatan Animasi Pendaptaran Siswa Baru pada SMAN 5 Kepahiang Berbasis Multimedia Linier Berbasis Multimedia Linier ini di harapkan nantinya akan dikembangkan menjadi lebih menarik dan kompleks.

3. Pada saat proses pembuatan animasi dan pengeditan video mengharuskan spesifikasi komputer yang memadai agar tidak menghambat dalam proses produksi

\section{DAftar Pustaka}

[1] Rinaldi, Jodi, dkk. 2012. Perancangan Tutorial Penerimaan Mahasiswa Baru Universitas Sam Ratulangi Berbasis Animasi 3D. Jurnal Teknik ElektroFT UNSRAT Manado

[2] Sartika, D. 2012. FILM ANIMASI 'PENDAFTARAN MAHASISWA BARU MENGGUNAKAN 3DS MAX: PEMODELAN MOBIL DAN ANIMASI. Paper Program Studi Teknik Informatika Universitas Gunadarma

[3] Watulingas, R.S, dan Lumenta, A.S. 2017. Animasi Prosedur Pendaftaran Calon Mahasiswa Baru Universitas Sam Ratulangi dengan AugmentedReality. Jurnal Teknik Informatika Universitas Sam Ratulangi, Volume 12, Nomor 1

[4] Maryati, Sri dan Bambang, E.P. 2013. Pembuatan Video Profil Sekolah Menengah Pertama Negeri 4 Polokarto Kabupaten Sukoharjo Dengan Menggunakan Multimedia. Jurnal Speed, Volume 5, Nomor 1. 